\title{
Wetting Technologies for High-Accuracy Sink-Float Separations in Water- Based Media
}

\author{
B. $\mathrm{Hu}^{*}, 1$, N. Fraunholz ${ }^{2}$ and P. Rem ${ }^{1}$ \\ ${ }^{I}$ Delft University of Technology, Faculty of Civil Engineering and Geosciences, Section Materials and \\ Environment/Recycling Technology, Stevinweg 1, 2628 CN, The Netherlands \\ ${ }^{2}$ Recycling Avenue, Delft, The Netherlands
}

\begin{abstract}
The accuracy of sink-float separations in water-based media such as Magnetic Density Separation is compromised by tiny air-bubbles attached to the surface of hydrophobic materials in the feed. Separations of plastics mixtures with accuracy better than $10 \mathrm{~kg} / \mathrm{m}^{3}$ require a total elimination of air-bubbles by pre-wetting the surface of the feed particles with a thin film of water. Theoretical and experimental results are compared for pre-wetting processes based on condensation from the gas phase and direct liquid-solid contact for both shredded waste and virgin polymers. The tests show that the wettability of most polymers improve slightly by steaming for about 1 minute, but the best wetting results are obtained with immersion in boiling tap water. The success of wetting in boiling water can be explained by the deposition of a thin layer of calcium carbonate. Shredded plastics are easier to be wetted than virgin polymers, probably because a relatively rougher surface is caused by the shredder process. A new wetting process to eliminate air bubbles was developed on the basis of these results, which carries a minimal amount of heat and water with the feed to the MDS process liquid.
\end{abstract}

Keywords: Plastics, polymers, polyolefin, wetting technology, wettability.

\section{INTRODUCTION}

Among all the widely used materials in consumer products, polymers are among the least recycled. Nowadays just one million tons of polyolefins are being recycled out of about 14 million tons yearly sold in Europe. Within the waste polymer resource, the plastics in complex wastes (WEEE, household waste, ASR) are largely unused because no cheap technology is available to produce high-purity products from such materials. In order to produce granulates of a quality comparable to materials produced from post-industrial waste; separation technology needs to be sensitive to very small differences in the physical properties of the materials. Moreover, in order to be economical and ecological, processes should recover most of the polyolefins in a useful product and minimize process residues. In 2009, an emerging technology called magnetic density separation (MDS) was applied to separate the various types of Polyolefins, polypropylene (PP), low-density polyethylene (LDPE), and high-density polyethylene (HDPE), from each other and from the contaminant materials, such as wood, rubbers and minor amounts of metals and foams [1]. The MDS technology is potentially cheap because it separates a complex mixture into many different materials in a single process step, using the same liquid. It is also very sensitive to small differences in material density, provided that the turbulence in the liquid can be accurately controlled. Results obtained with a small MDS laboratory setup showed that PP can be well separated from PE.

*Address correspondence to this author at the Department of Civil Engineering and Geosciences, Delft University of Technology, Delft, The Netherlands; Tel: +31-15-27 82897; Fax: +31-15-27 88162;

E-mail: Bin.Hu@tudelft.nl
In order to become a practical method for polyolefin separation, MDS technology must reach an accuracy of 10 $\mathrm{kg} / \mathrm{m}^{3}$ at commercially interesting production rates of $5 \mathrm{t} / \mathrm{h}$ or more. A major factor in separation quality, next to minimization of turbulence and quality control of the process liquid, is the entrainment of air bubbles in the feed. The focus of this paper is therefore on the efficiency of the wetting process, with the aim to eliminate air bubbles to less than $1 \%$ of the volume of the flakes, in order to avoid flotation of particles or variation of effective material density, both of which would affect the recovery of the polyolefins or introduce contaminants into the products.

Traditional methods for wetting plastic flakes prior to sink-float separation are wet grinding or friction washing. Practice with industrial wetting steps based on these methods show that a significant fraction of the heavy materials still end up in the float fraction. For example, in the separation of the polyolefins from PET $\left(1350 \mathrm{~kg} / \mathrm{m}^{3}\right)$, up to $2-5 \%$ of the input PET is found in the floats, showing that air bubbles may account for $35 \%$ of the volume of the flake. Experiments, in which the shear at the flake surface is increased by means of passing a high speed water flow (1 $\mathrm{m} / \mathrm{s}$ ) through a bed of plastics in between screens show a more efficient removal of air, but such a procedure is difficult to implement as a continuous process. An alternative to mechanical methods is to add surfactants to the process water or mix in compounds of intermediate hydrophilicity, such as alcohol. Such additives are known to effectively wet the plastics, but a disadvantage is that surfactants end up in the process liquid. In the case of MDS, the process liquid already contains a surface active component to stabilize the suspension of nano-size magnetite particles that make the liquid magnetic. The addition of 
surfactants for wetting is therefore compromising the quality of the process liquid. A third route to wet the surface of hydrophobic materials is by means of contacting with steam or boiling water. In these methods, the air is carried away with the steam and the surface of the particles is completely covered with water. The major issue with this route is that the magnetic process liquid degrades at high temperatures and the separation depends on the degree of dilution. This means that in carrying the plastics from the steam or hot water to the process liquid, a minimum of heat and water should be carried with it.

\section{THEORETICAL BACKGROUND OF WETTING TECHNOLOGY}

The most critical property of the polyolefin concentrates for separation by magnetic density separation process is the distribution of density of the various PP and PE components (Table 1). These distributions relate directly to the grade and recovery that can be accomplished with a certain cut density. About 80 mass \% of the PP from shredder residue has a density lower than $910 \mathrm{~kg} / \mathrm{m}^{3}$, whereas virtually all of the LDPE has a density higher than $910 \mathrm{~kg} / \mathrm{m}^{3}$. A sink-float process with a medium density of $910 \mathrm{~kg} / \mathrm{m}^{3}$ would therefore give good results for the PP product. With a separation accuracy of $10 \mathrm{~kg} / \mathrm{m}^{3}$, the PP recovery can reach $87 \%$ with an acceptable contamination of LDPE. For an accuracy of 20 $\mathrm{kg} / \mathrm{m}^{3}$, the PP recovery hardly changes, but the grade of the PP product is much lower, since over half of the total amount of LDPE now ends in the wrong product.

The presence of air bubbles attached to the surface of the plastic flakes is a major problem for separation errors. The effective density of a flake covered with air bubbles ( $\rho_{\text {effective }}$ ) is determined by the volume percentages of air $\left(\zeta_{\text {air }}\right)($ Eq. 1): $\rho_{\text {effective }}=\rho_{\text {plastic }} \cdot\left(1-\zeta_{\text {air }}\right)$

As shown in (Fig. 1), the effective density of the flakes decreases quickly with the volume of air bubbles. As little as $2 \mathrm{~mm}^{3}$ of air is able to create a separation inaccuracy of 10 $\mathrm{kg} / \mathrm{m}^{3}$. Polymer particles with a density between 910-920 $\mathrm{kg} / \mathrm{m}^{3}$ are then likely to mix with the PP product.

Table 1. Composition of PP, LDPE and HDPE in the Different Density Fractions of Shredder Residue [1]

\begin{tabular}{|c|c|c|c|}
\hline $\begin{array}{c}\text { Density Fraction } \\
\left(\mathbf{k g} / \mathbf{m}^{\mathbf{3}}\right)\end{array}$ & $\begin{array}{c}\text { PP \% } \\
\text { (Mass) }\end{array}$ & $\begin{array}{c}\text { LDPE \% } \\
\text { (Mass) }\end{array}$ & $\begin{array}{c}\text { HDPE \% } \\
\text { (Mass) }\end{array}$ \\
\hline \hline$<900$ & 72.4 & 0.0 & 0.9 \\
\hline $900-910$ & 6.9 & 0.0 & 0.3 \\
\hline $910-920$ & 16.3 & 18.0 & 1.0 \\
\hline $920-930$ & 1.1 & 82.0 & 3.4 \\
\hline $930-940$ & 0.8 & 0.0 & 26.1 \\
\hline $940-950$ & 0.3 & 0.0 & 33.5 \\
\hline $950-960$ & 0.1 & 0.0 & 18.0 \\
\hline $960-1000$ & 2.0 & 0.0 & 16.8 \\
\hline Total $<1000$ & 100.0 & 100.0 & 100.0 \\
\hline
\end{tabular}

Contacting with steam or boiling water may affect the wettability of plastic flakes in several ways. If the flakes are passed from an air atmosphere into pure steam and contacted with the steam for several seconds, a thin but continuous layer of condensate may possibly form on the surface. If such a thin film proves sufficiently stable against breaking up into individual droplets, the treated plastics may be mixed with the magnetic liquid straight away. Such a process would transfer a minimal amount of heat and water to the flakes

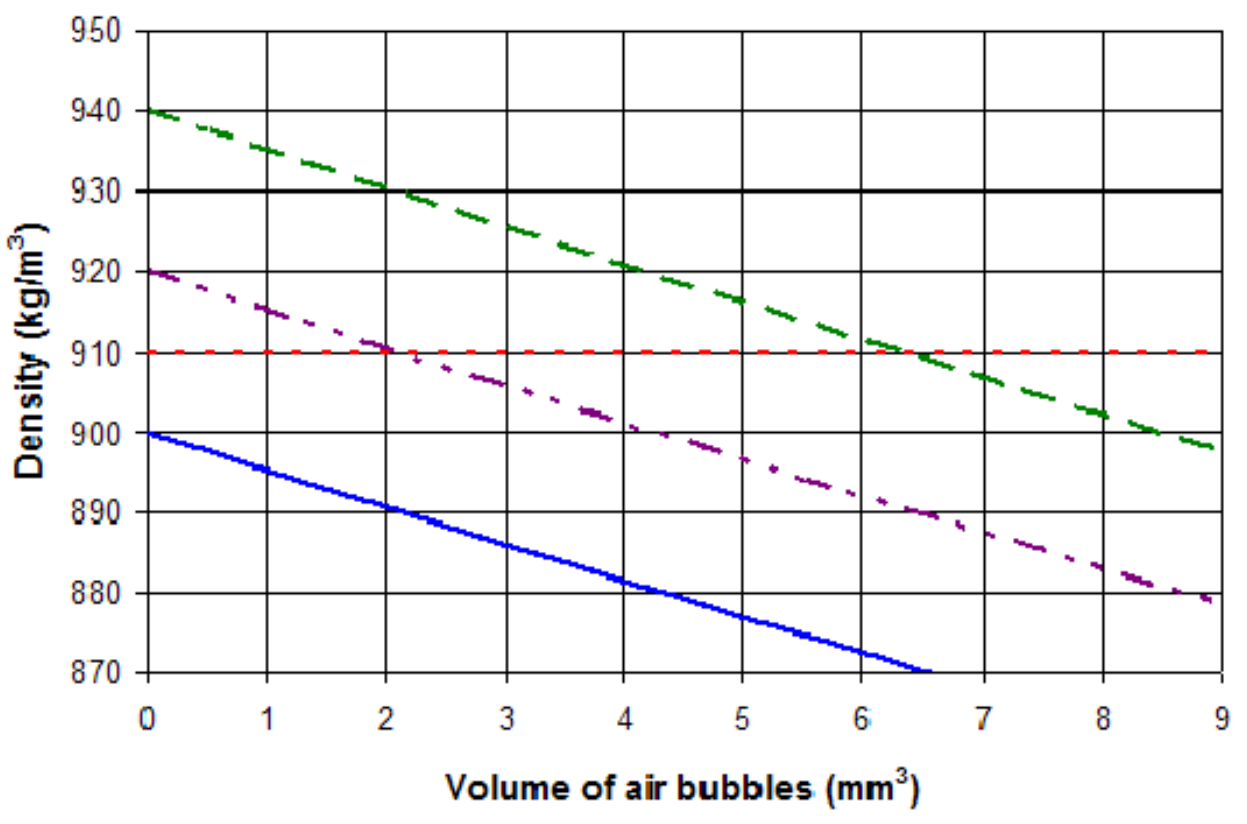

— PP - - - LDPE - - HDPE - - - Cut density

Fig. (1). Effective separation density of typical plastic flakes $\left(200 \mathrm{~mm}^{3}\right)$ covered with air bubbles. 
and therefore to the magnetic liquid. At the same time, it would be a fast and relatively simple process. Another possibility is to allow for a longer contact of the flakes with steam or boiling water. In this case, the plastics will be heated and a significant amount of water and heat is transferred to the flakes. In order to avoid heating and diluting the magnetic liquid, the flakes would then need to be cooled and at least partially dewatered before mixing them with the magnetic liquid. The most interesting issue in such processes is to see whether it is possible to create permanent or semi-permanent changes of the physical or chemical state of the flake surface, so that the wettability of the flakes remains high even after cooling and dewatering.

If a cold flake is introduced into a pure steam atmosphere, the so-called laminar boundary layer of air will mix with the steam in about $0.01 \mathrm{~s}$. As the flakes pass from the air into the steam, this thin boundary layer of air (typically $10^{-4} \mathrm{~m}$ ) will move with the flake surface. The time of diffusion between air and water vapor is [2] (Eq. 2):

$t=\frac{\delta_{\text {air }}^{2}}{D_{\text {air-vapor }}}$

Eq. 2

in which $\delta_{\text {air }}$ is the thickness of the laminar air layer and $D_{\text {air-vapor }}$ is the air-vapor diffusion coefficient $\left(10^{-5}\right.$ to $10^{-6} \mathrm{~m}^{2} \mathrm{~s}^{-}$

$\left.{ }^{1}\right)$ [3]. The equation shows that air is able to diffuse so fast into the surrounding steam that the air will not essentially influence the condensation process. After the air has been dissolved into the steam, the flake will be covered by a film of water which is caused by water vapor condensation. The vapor will condense on the surface of the flake at a rate which is controlled by the flux of heat into the interior of the flake. For the computation of the film thickness, the thermal capacity of the condensate film can be neglected. The water film thickness may be computed by numerical or analytical methods, using the equation for heat transfer in the interior of the flake (Eq. 3):

$\frac{d T}{d t}=\frac{\lambda_{p}}{C_{p} \rho_{p}} \frac{\partial^{2} T}{\partial x^{2}}$

Eq. 3

The parameters of this equation are the polymer thermal conductivity $\lambda_{p}$, the heat capacity $C_{p}$ and the density $\rho_{p}$. The boundary condition at the surface is assumed to be the condensation temperature of the steam, i.e., $\mathrm{T}=100^{\circ} \mathrm{C}$. The rate of condensation is controlled by the flux of heat at the surface (Eq. 4):

$\Phi=-\lambda_{p} \frac{\partial T}{\partial x}$

In the simulation presented in (Fig. 2), the PP and PE flakes were $2 \mathrm{~mm}$ thick, which is close to the flakes used in the experiments, and the initial temperature of the polymer was $20{ }^{\circ} \mathrm{C}$. The properties of PP and PE and the detailed information for the simulation are presented in Table 2. The numerical analysis shows that the temperature of PE rises faster than PP, as a result of the higher thermal conductivity and the lower heat capacity. The temperature of PE reaches the maximum in about $5 \mathrm{~s}$. The total heat content of the flake
$H_{t}$ at time $t$ relates to the thickness of water vapor $(h)$ on the polymer flake (Eq. 5):

$h_{t}=\frac{H_{t}-H_{0}}{\rho_{w} \cdot Q_{w}}$

in which $\rho_{w}$ is the density of water and $Q_{w}$ is the heat of evaporation.

Table 2. Parameters Adopted to Perform Simulation

\begin{tabular}{|c|c|c|c|}
\hline Parameter & PP & PE & Water (Vapor) \\
\hline \hline Thermal conductivity $\left(\mathrm{J} / \mathrm{s}^{-1} \mathrm{k}^{-1} \mathrm{~m}^{-1}\right)$ & 0.12 & 0.46 & \\
\hline Density $\left(\mathrm{kg} / \mathrm{m}^{3}\right)$ & 900 & 940 & 1000 \\
\hline Heat capacity $\left(\mathrm{J} / \mathrm{kg}^{-1} 1 \mathrm{~K}^{-1}\right)$ & 1925 & 1850 & \\
\hline Area $\left(\mathrm{m}^{2}\right)$ & 1 & 1 & \\
\hline Heat of water vapor $(\mathrm{kJ} / \mathrm{kg})$ & & & 2400 \\
\hline Temperature $\left({ }^{\circ} \mathrm{C}\right)$ & 20 & 20 & 80 \\
\hline Thickness $(\mathrm{mm})$ & 2 & 2 & \\
\hline$\Delta \mathrm{x}(\mathrm{mm})$ & 0.1 & 0.1 & \\
\hline$\Delta \mathrm{t}$ & 0.05 & 0.01 & \\
\hline
\end{tabular}

The final water film for both PP and PE flakes is around $120 \mu \mathrm{m}$ (Fig. 3), which is $6.7 \%$ of the polymer mass, but a thin film of $10 \mu \mathrm{m}$ could be established within less than a second. The ultimate film thickness is the same for PP and $\mathrm{PE}$ because of the similar heat capacities of both polymers.

Analytically, the water film thickness may be estimated by assuming that the heat will flow into the polymer surface to some depth $x$. It then follows that (Eq. 6 and 7):

$\frac{d T}{d t} \simeq \frac{\Delta T}{\Delta t} \simeq \frac{\lambda_{p}}{C_{p} \rho_{p}} \cdot \frac{\Delta T}{x^{2}}$

Eq. 6

$x=\sqrt{\frac{\lambda_{p} \Delta t}{C_{p} \rho_{p}}}$

The heat $H_{t}$ absorbed by the plastic flake is a function of $x$ and $\Delta T$ (Eq. 8):

$H_{t}=x \cdot \rho_{p} \cdot C_{p} \cdot \Delta T \cdot S$

Eq. 8

Since the heat released by the water vapor due to the condensation is the same as the energy absorbed by the polymer flakes (with area $S$ ) the water film thickness $\delta$ is given by (Eq. 9):

$\delta \cdot \rho_{\mathrm{w}} \cdot H_{\text {vapor }} \simeq \sqrt{\frac{\lambda_{p} \Delta t}{C_{p} \rho_{p}}} \cdot \rho_{p} \cdot C_{p} \cdot \Delta T \cdot S$

in which $\rho_{w}$ is water density, $H_{\text {vapor }}$ is water enthalpy. To a good approximation, the film thickness in the initial growth phase of the condensate film is (Fig. 3) (Eq. 10):

$\delta=2.4 \frac{\sqrt{\lambda_{\mathrm{p}} \Delta t \rho_{\mathrm{p}} C_{\mathrm{p}}}}{\rho_{\mathrm{w}} \cdot H_{\text {vapor }}} \cdot \Delta T \cdot S$

Eq. 10 


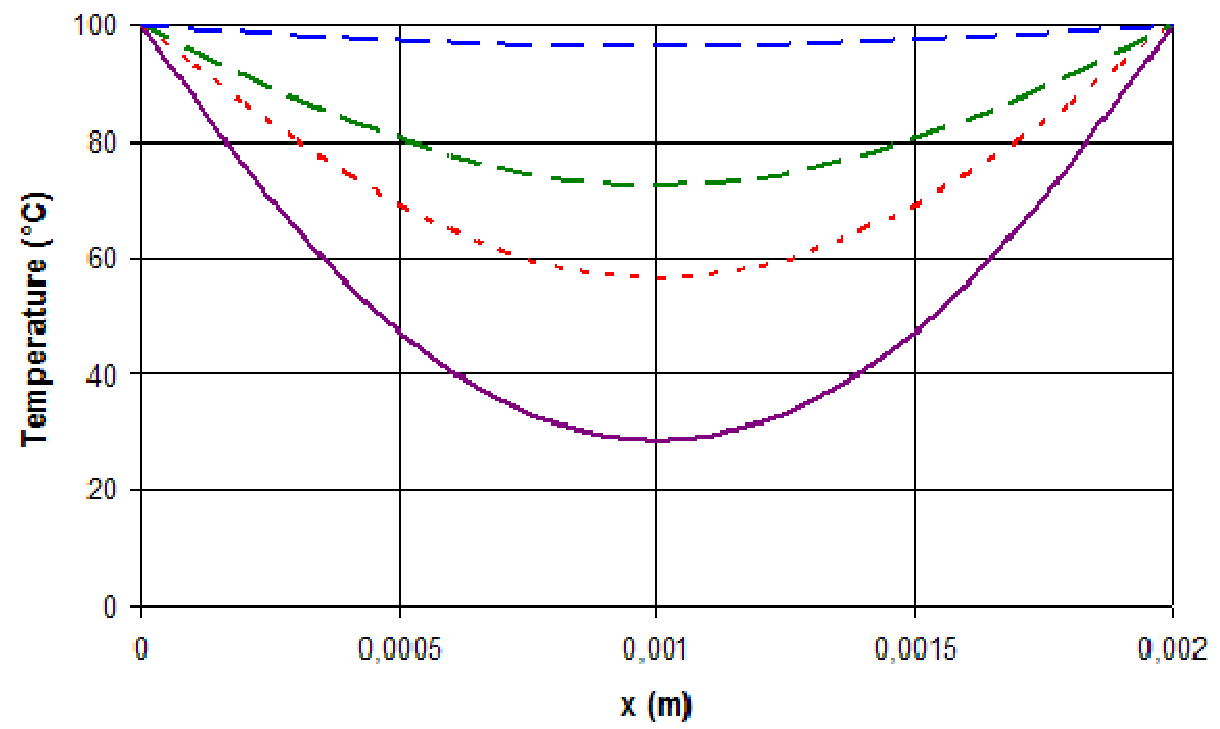

PP (2 seconds) - - - PP (5 seconds) - - -PE (2 seconds) - - -PE (5 seconds)

Fig. (2). PP and PE temperature profiles as a function of wetting time.

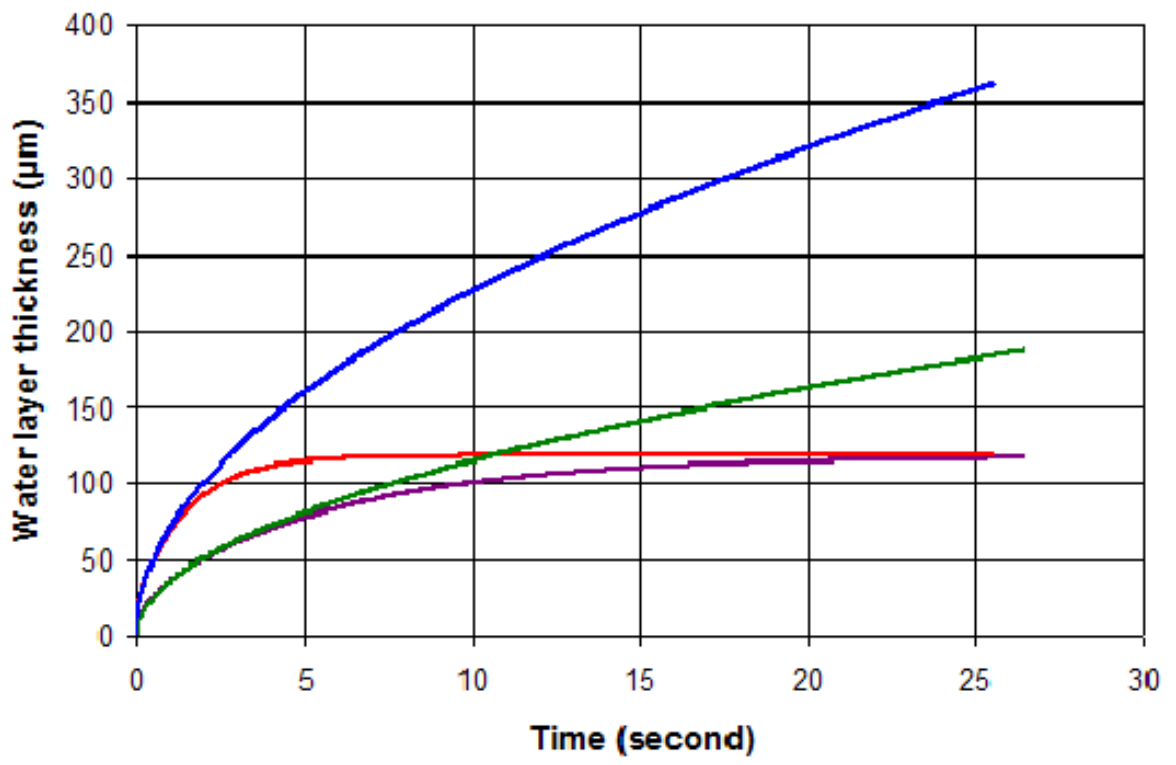

— PP (numerical) — PE (numerical) —PP (analytical) — PE (analytical)

Fig. (3). Numerical and analytical simulation of water film thickness for PP and PE flakes.

\section{MATERIALS AND EQUIPMENTS}

The materials used in the experiments included two types of shredded waste PS, virgin PS, virgin PP, LDPE, and HDPE, and shredded PET from waste bottles (Table 3). One of the shredded PS samples (PS1) consisted of simple flakes of $10-15 \mathrm{~mm}$ diameter and $0.5-1 \mathrm{~mm}$ thickness. Without wetting, $13 \%$ of this material floats in cold water. The other PS sample (PS2), with the same particle size range, contained a large proportion of twin-layer material of which some particles were partially split, forming a pocket of air in between the two layers. The shredded PET sample had a particle size between 5 and $10 \mathrm{~mm}$ and a thickness of 0.5 $\mathrm{mm}$.
Two types of process equipment were tested: a steam tube and a screw conveyor with steam injection. The steam tube consisted of a vertical section of transparent pipe, $0.4 \mathrm{~m}$ high and $12 \mathrm{~cm}$ diameter, in which the particles were fed from the top by a screw conveyor. The falling particles were contacted with a counter-current flow of low-pressure steam (Fig. 4). After passing through the steam in about $0.3 \mathrm{~s}$, the particles were collected in a stirred reservoir with cold water directly below the tube. A second type of equipment, an inclined screw conveyor with steam injection, is shown in (Fig. 5). The feed was introduced in the middle, together with a co-current flow of steam, and the material was again collected in a stirred reservoir of cold water. Part of the condensate was collected at the lower end of the conveyor. Apart from the tests with the two types of process 
Table 3. Basic Data of the Plastic Materials

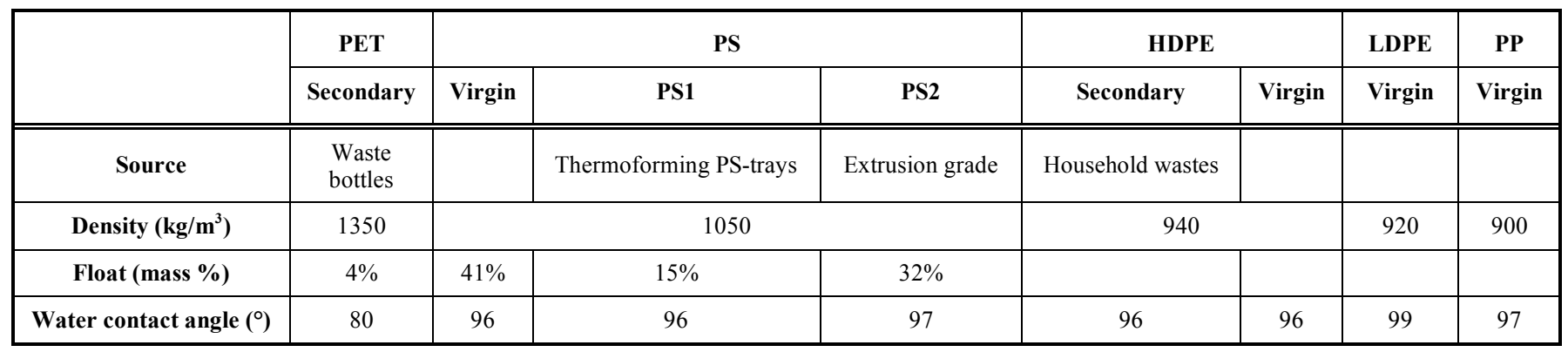

equipment, single particles were tested for wettability by contacting them with steam or boiling de-mineralized or tap water for periods of 10-60 s. The tests with the steam tube and steam screw were done with the shredded PS samples and the results were analyzed in terms of the fraction of floats. Since the density of PS is about $1050 \mathrm{~kg} / \mathrm{m}^{3}$, even a minor amount of air of $5 \%$, in volume, will result in floating of the flakes. The tests with single particles were done on all samples. The results of these tests were analyzed in terms of the volume of air bubbles, the water contact angles and the number of bubbles using a digital camera.

\section{RESULTS AND DISCUSSION}

Introductory tests were performed with the steaming tube on samples of shredded PS. It was found that it is very difficult to feed the flakes into the flow of steam individually because of the formation of sticky agglomerates of flakes due to condensing water near the exit of the screw. Flakes that were collected in the stirred reservoir showed very poor wetting. It was therefore suspected that the thin film of water produced by the contact with the steam is not stable. Later experiments with the steaming of individual flakes showed that, indeed, the water film quickly breaks up into droplets.

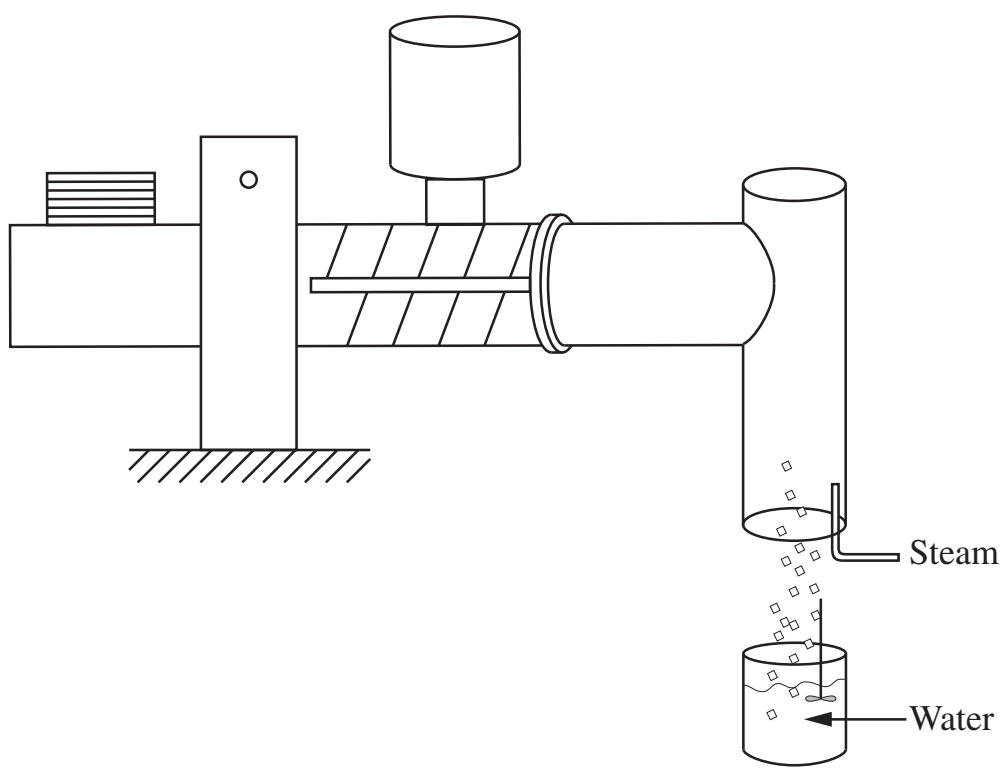

Fig. (4). Schematic draw representing the steam tube architecture.

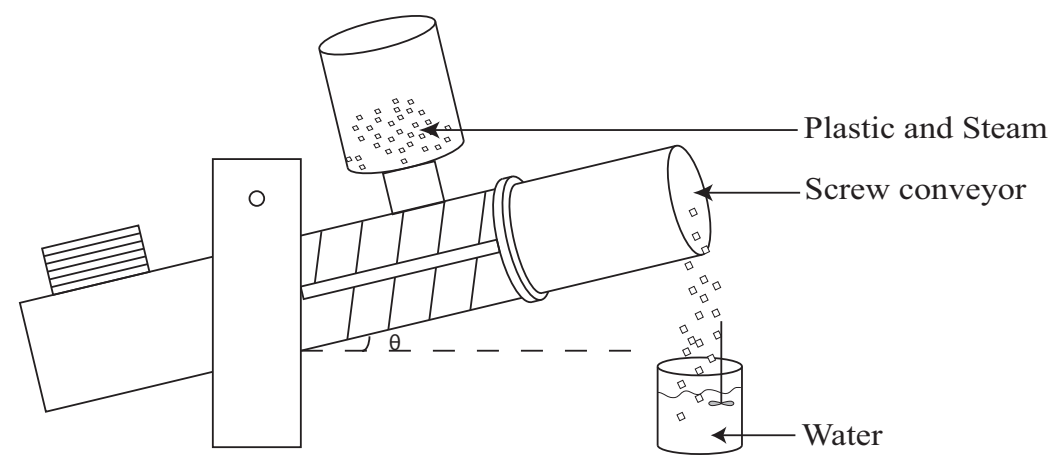

Fig. (5). Setup adopted to perform plastic particle wetting utilizing a steam screw conveyor. 
Table 4. Results of Tests with the Steaming Screw for PS1 and PS2 (in bold)

\begin{tabular}{|c|c|c|c|c|c|c|c|c|c|}
\hline \multirow{3}{*}{ Angle ( $(\theta)$} & \multicolumn{6}{|c|}{$2 \mathrm{KW}$} & \multirow{2}{*}{\multicolumn{3}{|c|}{$\begin{array}{c}4 \mathrm{KW} \\
\text { With Pre-Heating }\end{array}$}} \\
\hline & \multicolumn{3}{|c|}{ Without Pre-Heating } & \multicolumn{3}{|c|}{ With Pre-Heating } & & & \\
\hline & Residence Time & Sink & Float & Residence Time & Sink & Float & Residence Time & Sink & Float \\
\hline \multirow{2}{*}{$0^{\circ}$} & 1'09', & $91 \%$ & $8 \%$ & \multirow{2}{*}{$1 ’ 20 ’$} & \multirow{2}{*}{$93 \%$} & \multirow{2}{*}{$7 \%$} & \multirow{2}{*}{$1 ' 32 \prime$} & \multirow{2}{*}{$95 \%$} & \multirow{2}{*}{$5 \%$} \\
\hline & $1 ’ 20 ’$ & $93 \%$ & $7 \%$ & & & & & & \\
\hline \multirow{2}{*}{$12.5^{\circ}$} & $1 ’ 35^{\prime \prime}$ & $93 \%$ & $7 \%$ & & & & $1 ' 53^{\prime \prime}$ & $96 \%$ & $4 \%$ \\
\hline & $2 ’ 19^{\prime}$ & $96 \%$ & $4 \%$ & & & & 1'36', & $67 \%$ & $33 \%$ \\
\hline \multirow{2}{*}{$18.5^{\circ}$} & $26^{\prime}$, & $99 \%$ & $1 \%$ & \multirow{2}{*}{$2^{\prime} 09^{\prime \prime}$} & \multirow{2}{*}{$96 \%$} & \multirow{2}{*}{$4 \%$} & $1 ’ 24$ ', & $86 \%$ & $14 \%$ \\
\hline & 2'51', & $96 \%$ & $4 \%$ & & & & $2^{\prime} 50^{\prime \prime}$ & $97 \%$ & $3 \%$ \\
\hline
\end{tabular}

A second series of experiments were performed with both types of shredded PS (PS1 and PS2). Generally, the mass percentage of the sink fraction increased with the residence time. More than 90 mass \% of PS1 was well wetted after one minute, and $96 \%-99 \%$ after 2 to $3 \mathrm{~min}$ (Table 4). As expected, higher steam power compensates for shorter residence time. However, wetting was not much affected by the angle of inclination or by pre-heating of the steam screw. PS2 was significantly harder to be wetted compared to PS1. 67 mass \% PS2 was wetted after the stream screw, only $7 \%$ more than without any pre-wetting.

It was concluded from the steaming tests that condensation of a water film on the feed is not a robust wetting process, except for not too hydrophobic materials with a simple particle geometry that excludes pockets of air. For this reason, the alternative of contacting the plastics with boiling water was studied. In a first experiment, a reservoir with plastic flakes from the PS2 sample immersed in water was heated to study the behavior of the air bubbles. The results in (Fig. 6) show that, both the volume of the bubble and the contact angle increase with temperature. A simple explanation for the increasing bubble size is that with increasing temperature the original content of air in the bubble expands and at the same time is diluted with water vapor (see Table 5). However, the actual increase of the bubble diameter is much larger than predicted on the basis of these two effects and so air that was initially dissolved in the liquid around the bubble must also add to the volume of the bubble. In any case, the effect of the three mechanisms is that the bubble expands, lifts up and finally floats to the water surface. The contact angle of the air bubble, $53^{\circ}$ at $293^{\circ} \mathrm{K}$, almost doubled at $343^{\circ} \mathrm{K}$.

In a second experiment the improvement of the wettability of the plastics was studied before and after contacting with boiling tap water. As a first measure for the wettability, the water contact angles on the plastics before and after wetting were compared. As shown in (Fig. 7), the contact angles of PS1, PS2, and PET decreased significantly

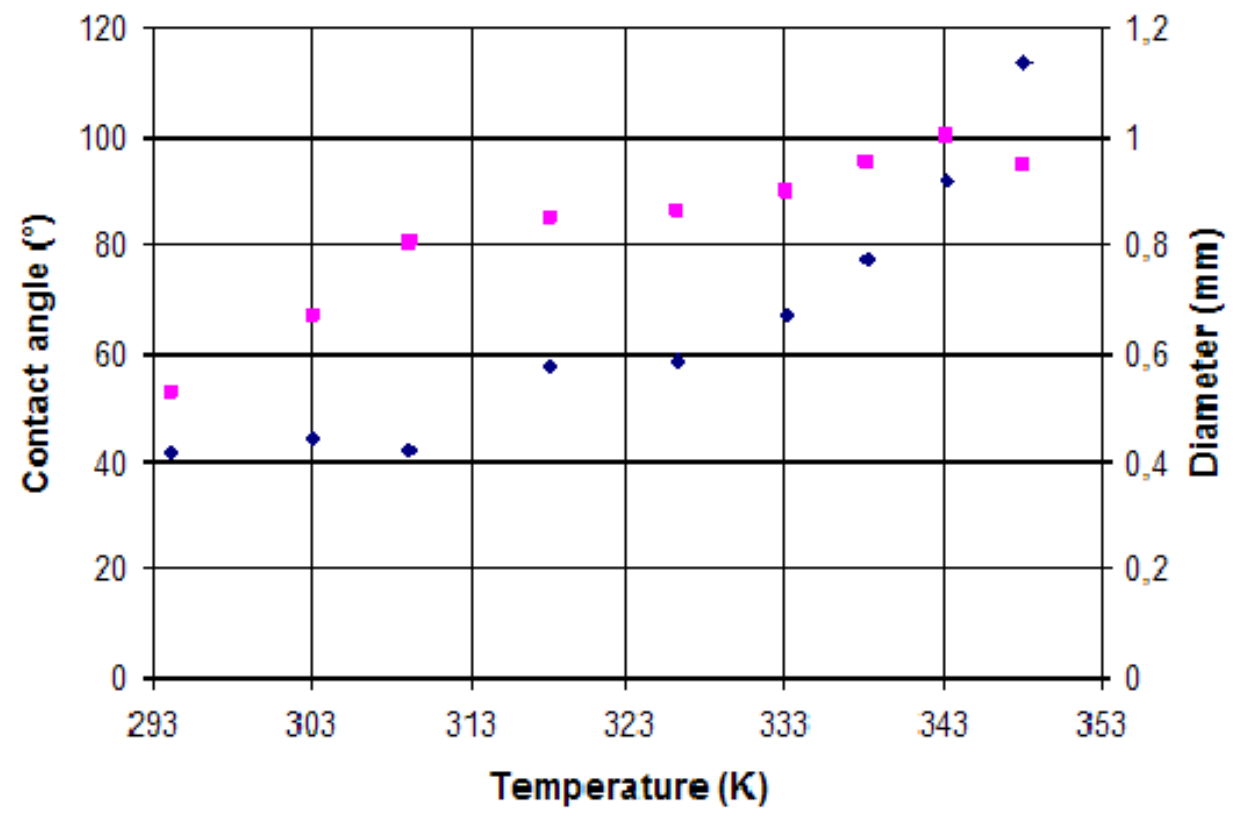

- Air contact angle - Diameter

Fig. (6). Bubble diameter and contact angle as a function of temperature during continuous heating. 
after $10 \mathrm{~s}$ of boiling while virgin PS and shredded HDPE showed a slower and less pronounced difference. Since a large contact angle corresponds to a hydrophobic surface, whereas a small contact angle implies a hydrophilic surface, the PS1, PS2, and PET evidently become hydrophilic after contact with boiling tap water. This is confirmed by recording the number of bubbles collecting on the uppersurface of the polymer flakes when immersed in water before and after contact with boiling water. It is clear that boiling tap water can effectively wet PS1, PS2 and PET, and improve the wettabilities of virgin PS and shredded HDPE (Fig. 8). Moreover, at least half a minute of boiling is necessary for a robust process. It was concluded from the correspondence between the results for the contact angle and the number of bubbles per unit surface area that the contact angle is a reliable and practical measure for the wettability of the flakes.
Table 5. Predicted Bubble Size as a Function of Temperature

\begin{tabular}{|c|c|c|c|}
\hline $\begin{array}{c}\text { Temperature } \\
\text { (K) }\end{array}$ & $\begin{array}{c}\text { Water Vapor } \\
\text { Pressure (Bar) }\end{array}$ & $\begin{array}{c}\text { Air Pressure } \\
\text { (Bar) }\end{array}$ & $\begin{array}{c}\text { Relative Bubble } \\
\text { Volume }\end{array}$ \\
\hline \hline 293 & 0.025 & 0.975 & 1 \\
\hline 313 & 0.08 & 0.92 & 1.13 \\
\hline 333 & 0.21 & 0.79 & 1.4 \\
\hline 353 & 0.50 & 0.50 & 2.3 \\
\hline 373 & 1.00 & 0.00 & $\infty$ \\
\hline
\end{tabular}

In order to understand the effect of contact with boiling tap water, the polymers were also wetted by steam and by contact with boiling de-mineralized water. The demineralized water was obtained by an ion-exchange de-

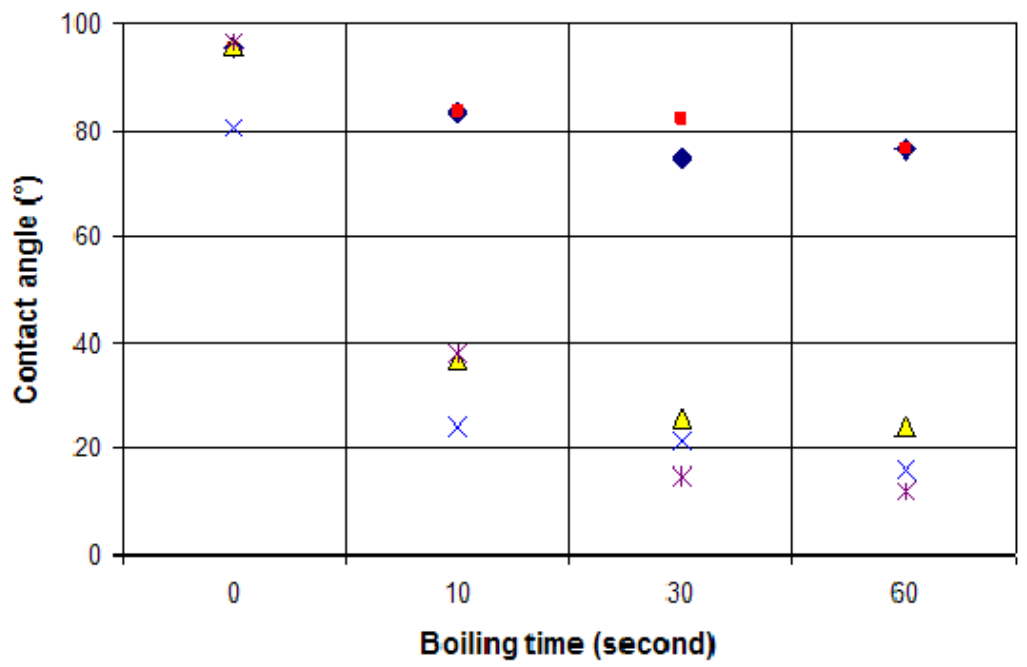

- PS (virgin) $-\mathrm{HDPE}$ (Shredded) $\triangle \mathrm{PS} 1 \times \mathrm{PET}$ (Shredded) $*$ PS2

Fig. (7). The contact angles of the plastics as a function of contact time with boiling tap water.

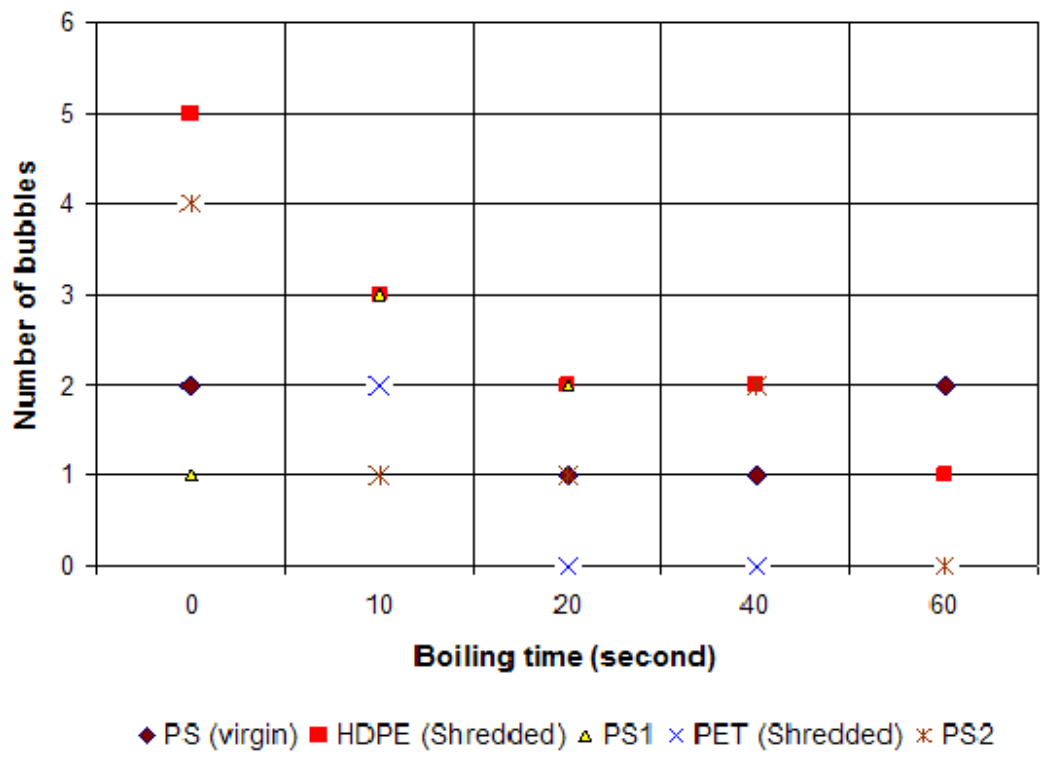

Fig. (8). The number of air bubbles on the upper-surface of the polymers as a function of contact time. 


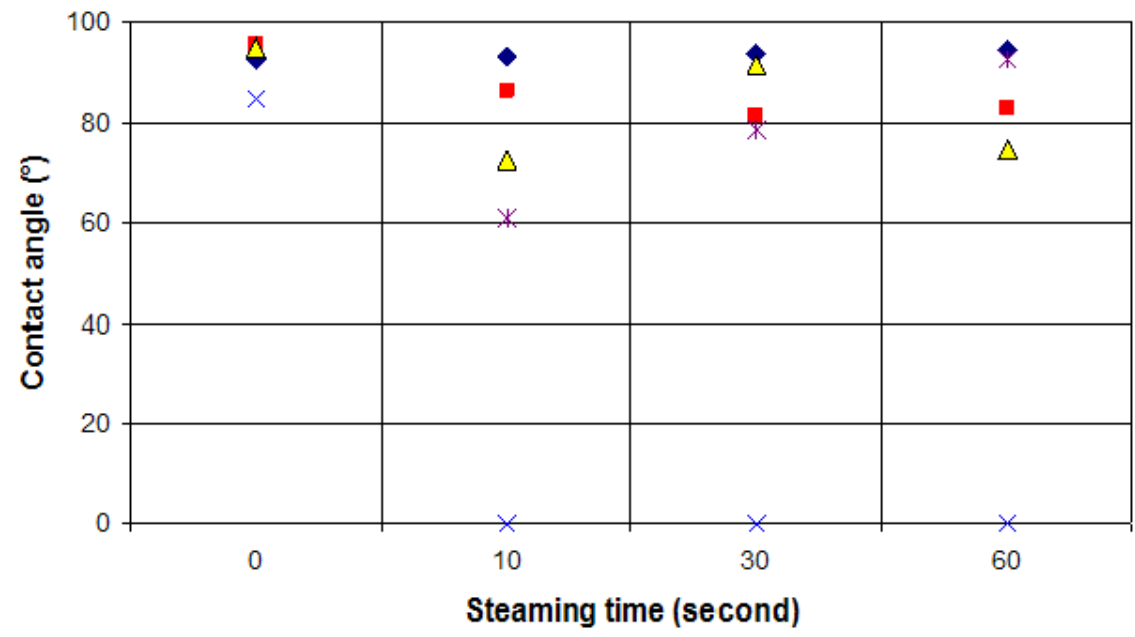

- PS (virgin) - HDPE (Shredded) $\triangle \mathrm{PS} 1 \quad \times$ PET (Shredded) $\quad *$ PS2

Fig. (9). The contact angles of the plastics after wetting by steam.

mineralizing device and the conductivity of the water was $0.08 \mu \mathrm{s} / \mathrm{cm}$. The wettability of most of the polymers, after exposure to steam for a few decades of seconds, were not strongly improved, except for the shredded PET, which is the least hydrophobic material to start with (Fig. 9). For some materials, the contact angle decreased initially; however, different from the boiling tap water results, there was no permanent effect on the wettability. The experiments with de-mineralized water present slightly better wetting on PS2: the contact angles of PS2 and PET were below $60^{\circ}$, but again, the results were significantly less positive than for boiling tap water.

Tap water contains a mixture of minerals. It was therefore suspected that the main difference of the wetting results with tap water versus steam and de-mineralized water is due to lime-scale created in the boiling process. Observation of a sample of virgin PS by a microscope showed that the contact angle was much smaller where a stain of lime-scale had been left by contact with tap water. The lime-scale, calcium carbonate $\left(\mathrm{CaCO}_{3}\right)$, is produced from calcium hydrogen carbonate $\left(\mathrm{Ca}\left(\mathrm{HCO}_{3}\right)_{2}\right)$ which is soluble in water:

$\mathrm{Ca}\left(\mathrm{HCO}_{3}\right)_{2} \rightarrow \mathrm{CaCO}_{3}+\mathrm{H}_{2} \mathrm{O}+\mathrm{CO}_{2}$

The reaction can be reversed if there is water and carbon dioxide.

$\mathrm{CaCO}_{3}+\mathrm{H}_{2} \mathrm{O}+\mathrm{CO}_{2} \rightarrow \mathrm{Ca}\left(\mathrm{HCO}_{3}\right)_{2}$

Further study proved that virgin PS was completely wetted, without extra heating, after adding a calcium carbonate layer artificially. The probable reason for the increased wettability of flakes treated with boiling water is therefore that a very thin layer of lime-scale was deposited on the plastic surfaces.

A further wetting test was done for virgin plastics. The results show that the wettability of virgin plastics hardly improve even after 1 minute of tap water boiling (Fig. 11).
Therefore, virgin polymers are harder to be wetted than shredded ones. A possible reason is that virgin plastics had a smoother surface or perhaps a surface coating. Since all the waste polymers were collected from a shredder, they rather have a rougher surface which affects the contact angle as well (Eq. 11).

The roughness $(r)$ of the surface is defined as:

$r=\frac{S_{\text {ture }}}{S_{p \text { r ojected }}}$

in which $S_{\text {ture }}$ and $S_{\text {projected }}$ are true and projected area of the surface, respectively.

For a rough surface, the contact angle is defined by Wenzel equation [4] (Eq. 12):

$\cos \theta_{\text {apparent }}=r \cdot \cos \theta_{\text {true }}$

Eq. 12

According to the equation, the roughness of a surface further decreases the contact angle if the contact angle is < $90^{\circ}$, whereas the roughness further increases the contact angle if the contact angle is $>90^{\circ}$. For this reason, a water layer is easier to be created on shredded plastics than on virgins.

Tests with the wetting procedure based on contacting plastics mixtures with boiling tap water showed that directly after taking the flakes from the water, the moisture content is typically about $10 \%$, which reduces to about $7 \%$ after cooling. Such an amount of water in the feed to the MDS process is results in acceptable rates of dilution, both economically and in terms of process liquid control.

\section{CONCLUSIONS}

Good wettability of polymers is essential for highaccuracy sink-float separation in water-based media such as MDS, because the grade and recovery of the products are critically influenced by even a small percentage of air bubbles. Both shredded waste and virgin polymers were contacted with steam and boiling water and the resulting 


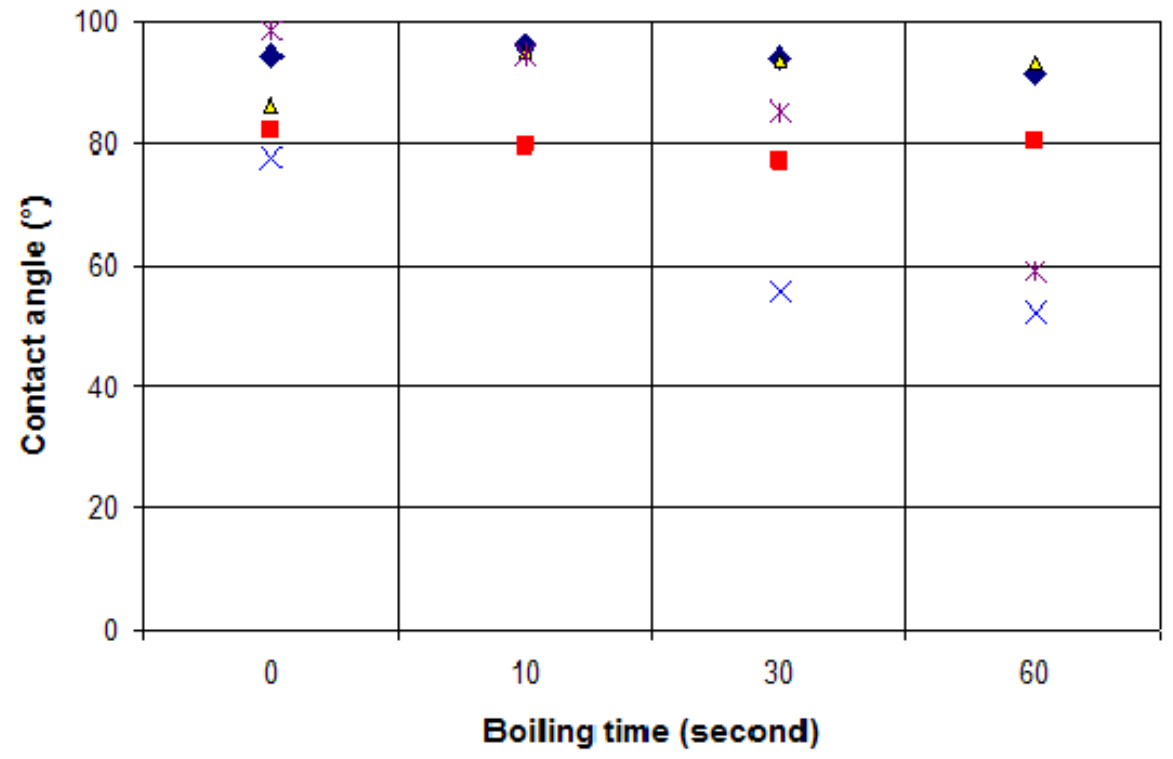

- PS (virgin) — HDPE (Shredded) $\triangle \mathrm{PS} 1 \times$ PET (Shredded) $*$ PS2

Fig. (10). The contact angles of the plastics after wetting with boiling de-mineralized water.

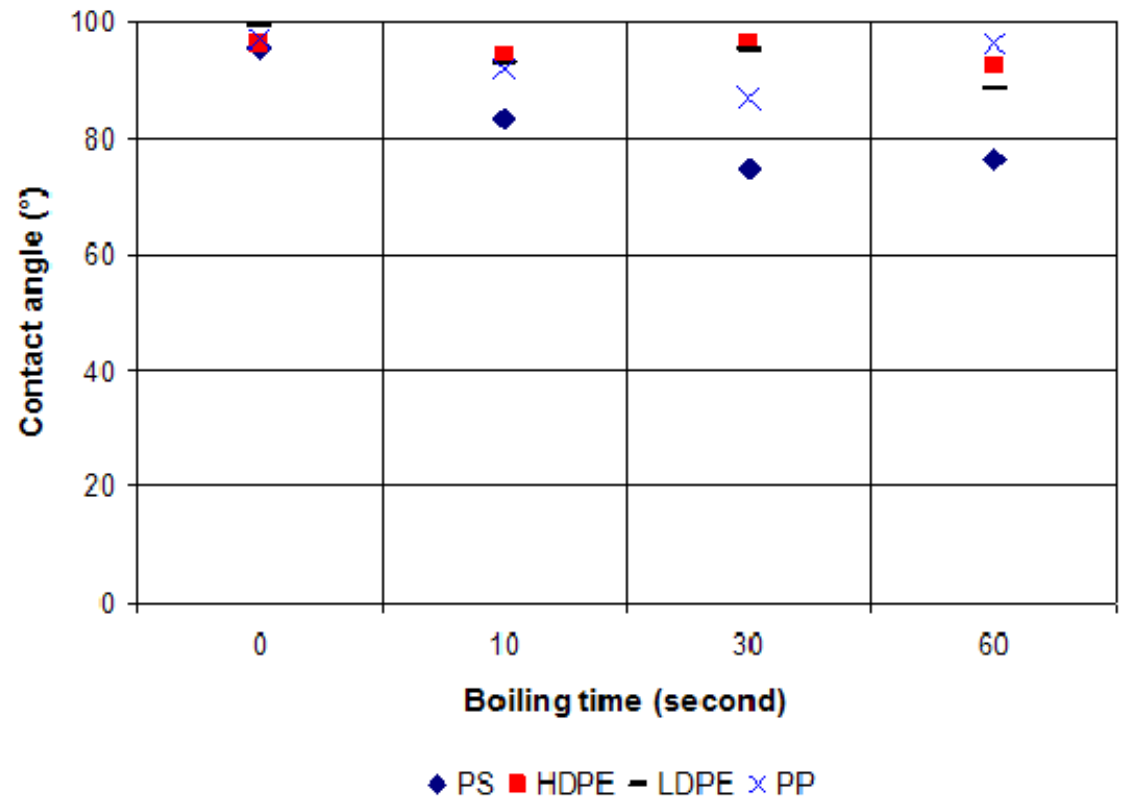

Fig. (11). Virgin plastic wettability after boiled in tap water.

wettability of the polymers was analyzed by means of measuring contact angles and counting the number of bubbles on the polymer surfaces. The tests show that the wettability of most polymers improve slightly by steaming for about 1 minute, but the best wetting results are obtained with immersion in boiling tap water. The success of wetting in boiling water can be explained by the deposition of a thin layer of calcium carbonate. Shredded plastics are easier to be wetted than virgin polymers, probably because a relatively rougher surface is caused by the shredder process. A new wetting process to eliminate air bubbles was developed on the basis of these results that carry a minimal amount of heat and water with the feed to the MDS process liquid.

\section{ACKNOWLEDGEMENTS}

The authors would like to thank Mr. A. Bosman for his help with the experiments and the European Commission for the financial support in the framework of the FP7 Collaborative project "Magnetic Sorting and Ultrasound Sensor Technologies for Production of High Purity Secondary Polyolefins from Waste (W2Plastics)". Grant Agreement No. 212782. 


\section{REFERENCES}

[1] E. J. Bakker, P. C. Rem, and N. Fraunholcz, "Upgrading mixed polyolefin waste with magnetic density separation", Waste Management, vol. 29, pp. 1712-1717, January 2009.
[2] J. A. Wesselingh and R. Krishna, Mass Transfer. London: Ellis Horwood Limited, 1990.

[3] G. Nellis and S. Klein, Heat Transfer. Cambridge: Cambridge University Press, 2008.

[4] B. W. Cherry, Polymer Surfaces. Cambridge: Cambridge University Press, 1981.

Received: October 19, 2009

Revised: November 5, 2009

Accepted: November 25, 2009

(C) Hu et al.; Licensee Bentham Open.

This is an open access article licensed under the terms of the Creative Commons Attribution Non-Commercial License (http://creativecommons.org/licenses/by$\mathrm{nc} / 3.0 /$ ) which permits unrestricted, non-commercial use, distribution and reproduction in any medium, provided the work is properly cited. 